\title{
Tranexamic acid
}

\section{reduces blood loss and transfusion in reoperative cardiac surgery}

Peter J. Dryden MSc MD, J. Patrick O'Connor MD, * W.R. Eric Jamieson MD, Ian Reid MD, * David Ansley MD, ${ }^{*}$ Heidar Sadeghi MD, Lawrence H. Burr MD, A. Ian Munro MD, Pamela M. Merrick BSN*

Purpose: The objective of this study was to assess the effect of tranexamic acid (TA), a synthetic antifibrinolytic, on blood loss and the need for transfusion of blood products following repeat cardiac valve surgery.

Methods: After ethics committee approval, 41 patients scheduled for reoperative valve replacement were enrolled in this randomized, double blind, placebo controlled study. Patients were randomized to receive $T A(10 \mathrm{~g}$ in $500 \mathrm{ml} \mathrm{NSaline)}$ or placebo (NSaline) as an iv bolus over $30 \mathrm{~min}$. after anaesthesia induction and prior to skin incision. Intraoperative blood loss was assessed by estimating blood volume on drapes, weighing surgical sponges, and measuring suction bottle returns. Postoperative blood loss was measured from mediastinal chest tube drainage following surgery. Blood products were transfused according to a standardized protocol.

Results: Patient demographics were similar for age, sex, cardiopulmonary bypass pump time, cross clamp time, surgical time, preoperative haemoglobin, coagulation profile, and the number of valves replaced during surgery. Tranexamic acid administration reduced intraoperative blood loss [median (range)] from 1656 (575-6270) to 720 $\mathrm{ml}(355-5616)(P<0.01)$ and postoperative blood loss from $1170(180-4025)$ to $538 \mathrm{ml}(135-1465)$ (Intent to Treat $n=41, P<0.01)$. The total red blood cells transfused (median, range) was reduced from $1500(0-9300)$ $\mathrm{ml}$ to $480(0-2850) \mathrm{ml}(P<0.01)$ in the TA group. In hospital complications and mortality rates were not reduced in the TA group.

Conclusion: Tranexamic acid reduced blood loss and the need for blood product transfusion and appears to be an effective treatment for patients undergoing reoperative cardiac valvular surgery.

Objectif : Évaluer l'influence de l'acide tranéxamique (AT), un antifibrinolytique synthétique, sur les pertes sanguines et le besoin de transfuser des produits sanguins après une réopération cardiaque valvulaire.

Méthodes : Après l'approbation du comité d'éthique, 41 patients ont été recrutés dans cette étude aléatoire. en double aveugle et contrôlée par placebo. Les patients ont été repartis aléatoirement pour recevoir de l'AT ( $10 \mathrm{~g}$ dans $500 \mathrm{ml}$ de sol.phys.) ou un placebo (sol. phys.) en bolus iv en $30 \mathrm{~min}$ après l'induction de l'anesthésie et avant l'incision de la peau. Les pertes sanguines peropératoires ont été évaluées en estimant le volume sanguin perdu dans les champs opératoires, en pesant les compresses, et en mesurant le volume sanguin recueilli par aspiration. À la période postopératoire, le sang recueilli par les drains médiastinaux a été mesuré. Les produits du sang ont été administrés selon un protocole standardisé.

Résultats : Les données démographiques étaient identiques pour l'âge, le sexe, la durée de circulation extracorporelle, du clampage et de la chirurgie, l'hémoglobine préopératoire, le bilan de la coagulation et le nombre de valves remplacées. L'administration d'AT a réduit les pertes sanguines peropératoires [médiane (écart)] de $1665(572-6270)$ à $720 \mathrm{ml}(335-5616)(P<0,01)$ et les pertes sanguines postopératoires de 1170 $(180-4025)$ à $538 \mathrm{ml}(\mid 35-1465)$ (Intention de traitement $n=41, P<0,01)$. Le nombre total des transfusions d'hématies (médiane, écart) a diminué de I $500(0-9300) \mathrm{ml}$ à $480(0-2850) \mathrm{ml}(P<0,01)$ dans le groupe AT. Le taux de complications et de mortalité n'a pas diminué dans le groupe AT durant l'hospitalisation.

Conclusion : L'acide tranéxamique diminue les pertes sanguines et le besoin de transfuser des produits sanguins et semble efficace pour les réopérations en chirurgie cardiaque valuulaire.

From the Department of Anaesthesia* and Division of Cardiovascular and Thoracic Surgery, Vancouver Hospital and Health Sciences Centre, University of British Columbia, Room 2449, 910 West 10th Avenue, Vancouver, B.C., V5Z 4E3 Canada.

Address correspondence to: Dr. J.P. O’Connor, Department of Anaesthesia, Phone: 604-875-4304; Fax: 604-875-5209;

E-mail: poconnor@vanhosp.bc.ca

Presented at the Annual Meeting of the Canadian Anaesthetists' Society, June 14-18, 1996 in Montréal, Québec.

Accepted for publication April 20, 1997. 
$\mathrm{E}$ XCESSIVE blood loss after cardiac surgery is an area of concern for all operating room and intensive care personnel. Due in part to the effect of extracorporeal circulation on haemostatic mechanisms, there is often a need for transfused blood products following cardiovascular surgery. ${ }^{1}$ The benefits of decreasing blood loss include reducing potential transmission of serious viral infections, improved operative outcomes, reducing operating room time, and containment of transfusion costs. In addition to current methods for reducing blood loss such as normovolaemic haemodilution, intraoperative autotransfusion, and postoperative return of mediastinal shed blood, an effort has been made to use a pharmacological approach to reduce surgical blood loss. However, no medication can replace the need for delicate and painstaking surgical dissection and attention to intraoperative haemostasis. Aprotinin has been the most widely studied antifibrinolytic that has been shown to reduce blood loss and the need for transfusion of blood products in patients having reoperation involving cardiopulmonary bypass. ${ }^{2-6}$ Reoperative cardiac surgery has a greater risk for bleeding and the need for transfusion due to tedious dissection of scarred and obscured landmarks.

The synthetic antifibrinolytics, epsilon-aminocaproic acid, and the more potent tranexamic acid form reversible complexes with plasminogen and remove it from the fibrin surface retarding fibrinolysis. ${ }^{7}$ Thus, tranexamic acid retards the resolution of fibrin clots, leading to haemostasis. The clinical uses of tranexamic acid (TA) include the prevention of excessive bleeding after tonsillectomy, in prostatic surgery, after cervical conization, and in primary intrauterine device-induced menorrhagia. ${ }^{8}$ The effect of TA on haemostasis in cardiac surgery has recently been investigated and suggests that this agent reduces blood loss. ${ }^{9-15}$ A recent metaanalysis investigating prophylactic drug treatment supports the use of TA, $\xi$-aminocaproic acid and aprotinin for reduction of postoperative bleeding. ${ }^{16}$ With primary elective coronary artery bypass grafting (CABG) operations, one study reported that tranexamic acid reduced postoperative bleeding, but its benefit was outweighed by the potential risk of thrombosis. ${ }^{17}$ Thus far, all the above studies document a reduction of bleeding in primary CABG surgery, but do little to address the main reason for decreasing blood loss which is to decrease the need for transfusion in patients undergoing cardiac surgery.

In our centre, most of the blood product utilization takes place in patients undergoing reoperative cardiac surgery. Due to the theoretical risk of thrombosis and concern about the use of antifibrinolytics in myocardial revascularization, we elected to target a patient population undergoing cardiac valve surgery. Therefore, in this randomized, double blind, placebo controlled study, the effect of TA on bleeding and transfusion of blood products was assessed in patients undergoing repeat cardiac valvular surgery.

\section{Methods}

Before the start of this investigation, a proposal was approved by the UBC ethics review board and subsequently patients were enrolled into this study. Following informed consent, patients over $18 \mathrm{yr}$ of age undergoing elective reoperative cardiac valve surgery were approached for enrollment. Patients were excluded if there was a history of thrombosis, pre-existing coagulopathy, creatinine $>250 \mathrm{mg} \cdot \mathrm{dl}^{-1}$, or a known allergy to TA. A history of thrombosis referred to previous deep vein thrombosis, disseminated intravascular coagulation, non-cmbolic stroke within six months, unstable angina, or bleeding into the renal tract. Patients undergoing surgery between June, 1993 and May, 1995, were randomized to receive TA (Cyklokapron) (10 g in $500 \mathrm{ml}$ normal saline (NS)) or placebo (NS). The "study drug" was mixed by independent ICU personnel and the medication was infused after anaesthesia induction as an ip bolus over $\mathbf{3 0} \mathrm{min}$ prior to skin incision. Patients were requested to discontinue aspirin up to five days before operation and patients with coumadin-induced anticoagulation were reversed within the perioperative period to ensure that the INR was in the normal range.

A standardized anaesthetic technique was used that included premedication with lorazepam, induction with midazolam and sufentanil and maintenance with isoflurane. After anaesthesia induction, vecuronium or pancuronium was administered to aid tracheal intubation and provide muscle relaxation. The lungs were ventilated with air, oxygen and isoflurane. Beef lung heparin $\left(300 \mathrm{u} \cdot \mathrm{kg}^{-1}\right)$ provided anticoagulation for extracorporeal circulation (ECC). The automated activated coagulation time (Kaolin based Hepcon $^{\mathrm{R}}$ ) was maintained $>450$ sec to ensure anticoagulation. For all patients, the ECC used non-occlusive roller pumps, membrane oxygenators, cold $\left(7^{\circ} \mathrm{C}\right)$ sanguinous cardioplegic arrest as well as controlled systemic hypothermia $\left(28-32^{\circ} \mathrm{C}\right)$. After ECC, protamine (1 mg.100 $\mathrm{U}^{-1}$ heparin) reversed heparin anticoagulation to achieve an activated coagulation time near baseline prior to chest tube connection. Protamine $(50 \mathrm{mg})$ was given if required at one and two hours postoperatively if thrombin time was $>25 \mathrm{sec}$.

Blood loss was measured intraoperatively as well as postoperatively. In the operating room, an estimation of blood loss was made by having operating room personnel weigh sponges, measure suction bottle returns, and 
assess blood loss on operative drapes. All mediastinal blood loss after heparin administration and before protamine reversal was returned to the patient via ECC and autotransfusion in the ICU. Postoperative blood loss was measured from mediastinal chest tubes placed during surgery. Chest tube drainage ( $>200 \mathrm{ml}$ ) was autotransfused in the ICU. Patients who suffered excessive postoperative bleeding that required exploratory thoracotomy were excluded from the efficacy analysis of this study.

A standardized protocol was used as a guide for transfusion of blood products. One unit of autologous blood reinfused from the start of surgery or reinfusion of chest tube drainage was not considered as blood products given. Red blood cells were transfused for haematocrit $<0.24$ or haemoglobin $<80 \mathrm{~g} \cdot \mathrm{l}^{-1}$ or active bleeding with cardiovascular instability as assessed clinically. Active bleeding was referred to as chest tube drain losses $>200 \mathrm{ml} \cdot \mathrm{hr}^{-1}$ over two consecutive hours or $>800 \mathrm{ml}$ over four hours. Fresh frozen plasma was given for documented factor deficiencies or active bleeding in association with prolonged PTT or abnormal INR. Platelet transfusion was used for platelet counts $<50,000 \cdot \mathrm{cm}^{-3}$ or active bleeding in unstable patients that were considered to be oozing from sites other than chest tube drains.

A comparison was made analyzing demographic data, blood loss, and the transfusion of blood products. Categorical data were analyzed using Chi-square or Fisher's exact tests as appropriate. All numerical data were tested for normality of distributions using the Martinez-Iglewicz, the Kolmogorov-Smirnov and the D'Agostino-Pearson Omnibus $\mathrm{K}^{2}$ normality tests as performed by the NCSS computer programme, version 5.03. Normally distributed data were analyzed for between-group differences by unpaired $t$ tests. Those data that were skewed were analyzed using MannWhitney tests. Variables measured at different times that were normally distributed were not eligible to be analyzed with repeated measures ANOVA due to the lack of compound symmetry. These variables were analyzed for between group differences at each point using Mann-Whitney tests, with Bonferonni's correction. $P<0.05$ was considered significant. Bonferroni's correction was used for data measured multiple times.

\section{Results}

Forty-one patients were enrolled in the study with 19 in the placebo group and 22 in the TA group. Two patients were removed from the efficacy analysis because of the need to return to the operating room for mediastinal exploration for active bleeding: both were in the placebo group. There were no differences in the demographic variables of the two treatment groups (Table I). The groups were comparable with respect to age, weight, sex, surgical time, ECC time, cross-clamp time, complications, length of stay in hospital, mortality, or the number of valves replaced. There were 15 mitral valve replacements (five placebo, $10 \mathrm{TA}$ ), nine aortic valve replacements (five placebo, four TA), six combined mitral and aortic valve replacements (three placebo, three TA), six combined mitral and tricuspid valve replacements (two placebo, four TA), one tricuspid valve replacement, and one triple valve replacement. Although not anticipated preoperatively, three operations required coronary artery bypass grafting in addition to valve replacement. There were no differences in haemoglobin, haematocrit, platelet count, or coagulation studies( PTT or PT) preoperatively or postoperatively (Table II).

The results of the blood loss measured intraoperatively, postoperatively, and total are presented in Figures 1, 2 , and 3 , respectively. In both the intent-to-treat and efficacy analysis, there was a reduction in intraoperative, postoperative, and total blood loss in the tranexamic acid group. Since there was no difference in the analysis of intent-to-treat and efficacy, the intent-to-treat group with all the enrolled patients is presented in the figures. One patient was suspected to have acquired a pump coagulopathy and was an outlier in the data of the tranexamic acid group, but was not excluded from the analysis. With this outlier excluded, the results of the tranexamic acid group were not changed with blood loss of $700 \mathrm{ml}$, $535 \mathrm{ml}$, and $1309 \mathrm{ml}$ for intraoperative, postoperative, and total blood loss, inclusively.

TABLE I Demographic variables for parient groups [mean \pm S.D., median (range), and count (\%)]

\begin{tabular}{lll}
\hline Clinical Variable & Placebo & Tranexamic Acid \\
\hline $\mathrm{n}$ & 19 & 22 \\
Age (yr) & $61 \pm 12.5$ & $63 \pm 12.6$ \\
Weight $(\mathrm{kg})$ & $64 \pm 18$ & $65 \pm 12$ \\
Sex $(\mathrm{M} / \mathrm{F})$ & $8 / 11$ & $9 / 13$ \\
Single valve & 12 & 15 \\
Double valve & 6 & 7 \\
Triple valve & 1 & 0 \\
Surgical Time (min.) & $317(207-680)$ & $265(185-556)$ \\
ECC* (min.) & $178 \pm 73$ & $150 \pm 52$ \\
Cross clamp time (min.) & $104(48-282)$ & $100(49-191)$ \\
L.O.S. ${ }^{\dagger}$ (days) & $12(2-59)$ & $10(6-62)$ \\
Complications ${ }^{\ddagger}$ & $1(0-6)$ & $1(0-7)$ \\
Mortality & $4(21 \%)$ & $1(4.5 \%)$ \\
\hline
\end{tabular}

* Extracorporeal circulation,

$\dagger$ length of stay in hospital after surgery

$\ddagger$ in hospital events that required consultation of other hospital services 
TABLE II Haematological variables for patient groups.

\begin{tabular}{|c|c|c|c|}
\hline Clinical Variable & $\begin{array}{l}\text { Placebo } \\
n=19\end{array}$ & $\begin{array}{l}\text { Tranexamic Acid } \\
n=22\end{array}$ & P value \\
\hline Preop. PTT (sec) & $26.9(23.0-79.6)$ & $27.7(23.8-63.4)$ & 0.8430 \\
\hline PTT after ECC * $(\mathrm{sec})$ & $32.2(24.1-52.9)$ & $27.9(23.5-58.6)$ & 0.4921 \\
\hline PTT after $\mathrm{POD}^{\dagger} \# 5$ & $27.1(20.4-37.3)$ & $26.6(19.6-40.3)$ & 0.8368 \\
\hline Preop. PT (sec) & $12.8(11.1-16.6)$ & $12.8(11.3-19.3)$ & 0.8430 \\
\hline$P T$ after $E^{*} C^{*}(\mathrm{sec})$ & $15.7(11.8-19.0)$ & $15.6(13.7-20.9)$ & 0.4299 \\
\hline $\mathrm{PT}$ after $\mathrm{POD}^{\dagger} \# 5$ & $13.1(12.3-15.9)$ & $13.8(11.4-19.0)$ & 0.2726 \\
\hline Preop. Hct. (\%) & $0.38 \pm 0.05$ & $0.39 \pm 0.05$ & 0.9123 \\
\hline Hct. after ECC ${ }^{\star}(\%)$ & $0.25 \pm 0.06$ & $0.28 \pm 0.03$ & 0.1139 \\
\hline Hct. after POD $^{\dagger} \# 5$ (\%) & $0.29 \pm 0.05$ & $0.29 \pm 0.03$ & 0.6269 \\
\hline Preop. Hgb & $128 \pm 18$ & $132 \pm 19$ & 0.7605 \\
\hline $\mathrm{Hgb}$ after $\mathrm{ECC}^{\star}$ & $85 \pm 19$ & $96 \pm 10$ & 0.1308 \\
\hline $\mathrm{Hgb}$ after $\mathrm{POD}^{\dagger} \# 5$ & $97 \pm 17$ & $99 \pm 11$ & 0.5991 \\
\hline Preop. Plt count & $228 \pm 63$ & $200 \pm 80$ & 0.2659 \\
\hline Plt count after ECC* & $108 \pm 32$ & $122 \pm 51$ & 0.0672 \\
\hline Plt count after $\mathrm{POD}^{\dagger} \# 5$ & $169 \pm 72$ & $215 \pm 87$ & 0.1624 \\
\hline
\end{tabular}

Haematological variables including partial thromboplastin time (PTT) and prothrombin time (PT), haemoglobin (Hgb), platelet (Plt) count, and hacmatocrit (Hct.) for patient groups (mean $\pm \mathrm{SD}$, median (range)

"Extracorporeal circulation, ${ }^{\dagger}$ postoperative day

Total red blood cell $(1$ Unit $=$ approx. $360 \mathrm{ml})$ (Figure 4) and plasma transfusion (Figure 5) were reduced in the tranexamic acid group in both the intent-to treat and efficacy analysis. The placebo group received more blood products intraoperatively, in the ICU, and in total, but there was no difference in blood product utilization on the ward. The total volume of platelets and albumin (25\%) received in the tranexamic acid group was reduced in the intent-to treat group (Figure 6), but there was no difference in the efficacy analysis. Thus, the antifibrinolytic effect of

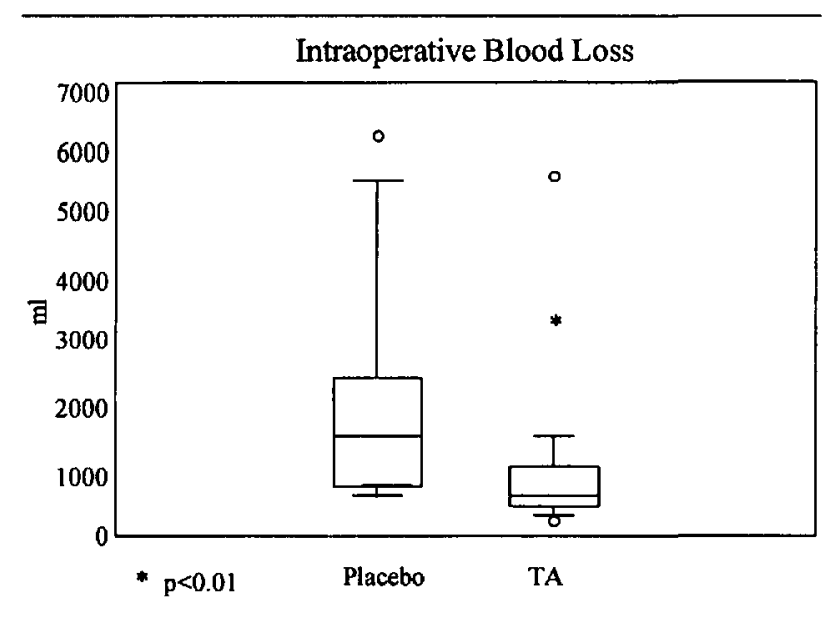

FIGURE 1 Intraoperative blood loss (suction, sponges, drapes) in tranexamic acid and placebo groups. tranexamic acid had its greatest effect on red blood cell and plasma transfusion, which were the blood products most commonly transfused in this study.

There was a median of one complication in both groups of patients while in hospital. Mortality rates were not different in either of the treatment groups with $21 \%$ mortality in the placebo group and $4.5 \%$ in the tranexamic acid group $(P=0.1644)$. Table III shows the causes of death in this study that occurred before hospital discharge and post-operative day of mortality.

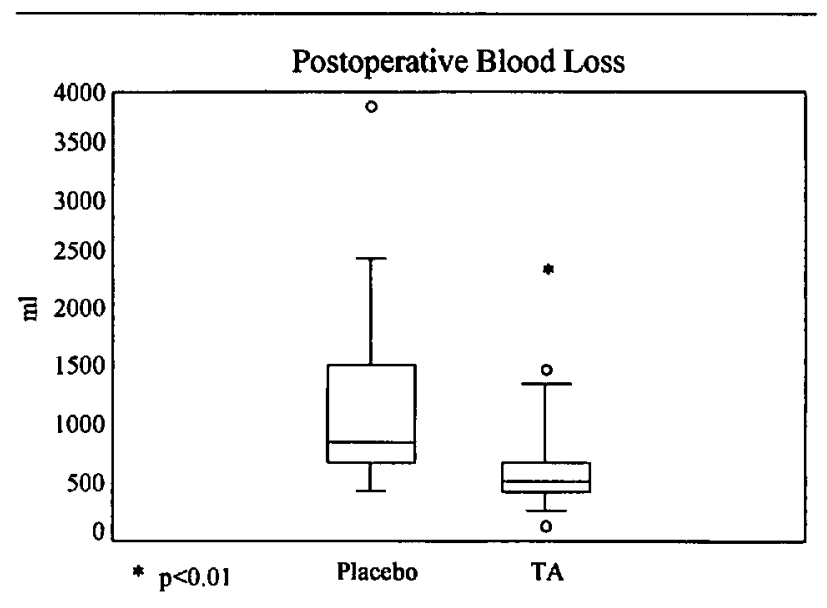

FIGURE 2 Postoperative blood loss (mediastinal chest tubes) in tranexamic acid and placebo groups. 


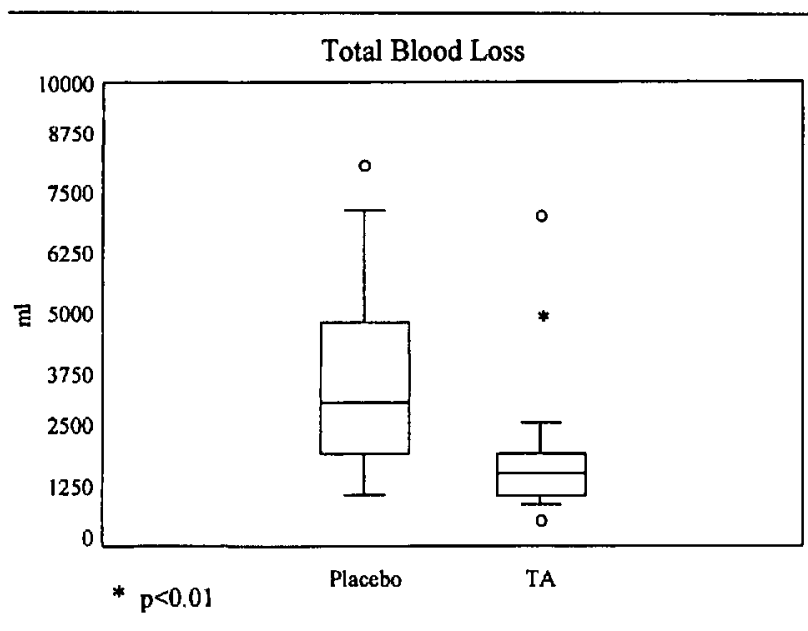

FIGURE 3 Total blood loss in tranexamic acid and placebo groups.

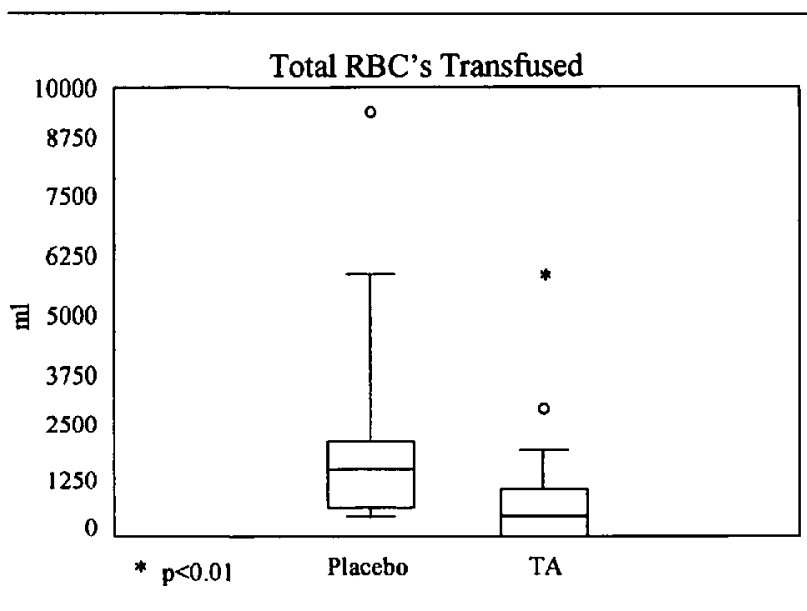

FIGURE 4 Total packed red blood cells transfused.

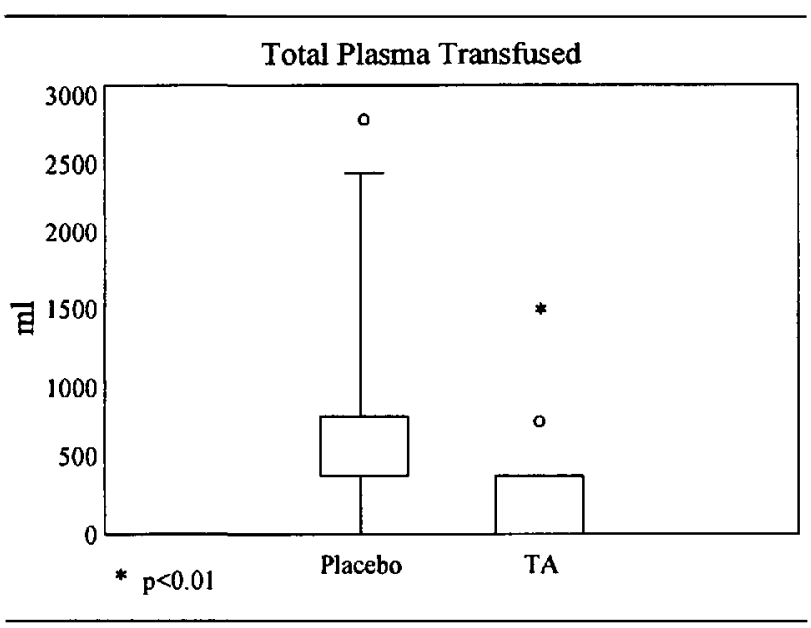

FIGURE 5 Total plasma transfused.

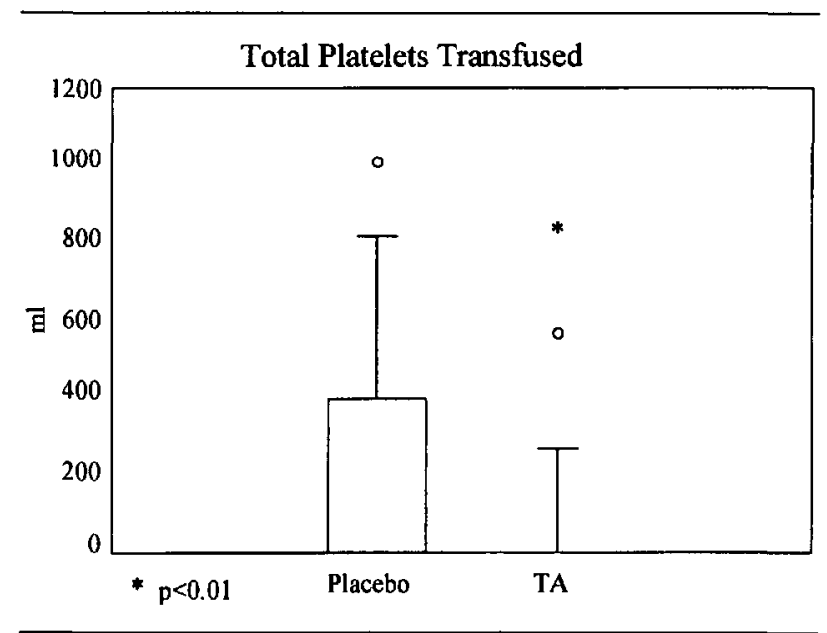

FIGURE 6 Total platelets transfused.

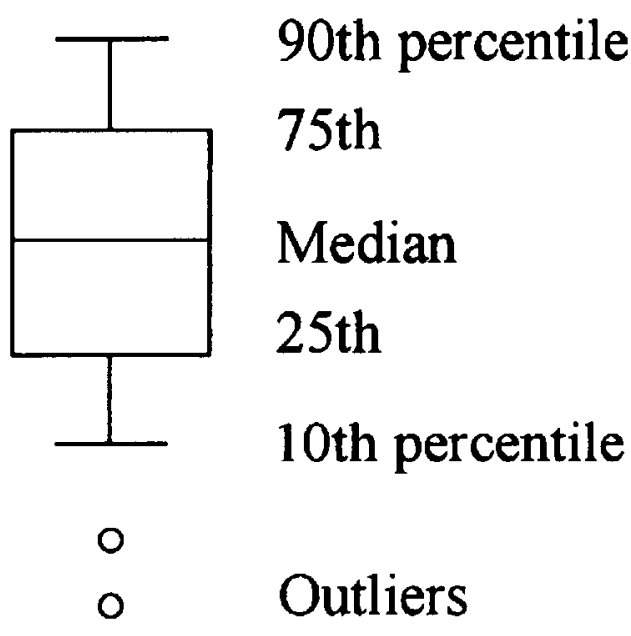

FIGURE KEY

\section{Discussion}

Excessive bleeding is a common postoperative complication following cardiopulmonary bypass. The present study investigated the effect of tranexamic acid on blood loss during cardiac surgery in a placebo controlled study. The groups were comparable with respect to demographics and the type of operative procedure performed. Our results demonstrate that prophylactic TA administration considerably reduced both blood loss and the transfusion of blood products in patients undergoing elective reoperative valve replacement. Total blood loss was decreased by $>50 \%$ and the transfusion of red blood cells was reduced by $>60 \%$. In particular, there was a decrease in transfusion of blood products intraoperatively and in the intensive care unit. 
TABLE III Causes of Mortality (postoperative day) for patient groups

\begin{tabular}{lcl}
\hline Group & Patient \# & Cause of death (post-operative day) \\
\hline Placebo & 7 & respiratory failure, ARDS (14) \\
& 9 & delerium, suicide (18) \\
& 11 & pulmonary haemorrhage, \\
& 18 & respiratory failure, cardiac arrest (25) \\
TA & 34 & cardiac arrest (1) \\
\hline
\end{tabular}

Previous studies assessing the efficacy of TA in cardiac surgery have revealed mixed results. Some have not demonstrated a reduction in the transfusion of blood products ${ }^{15,17}$ whereas others indicate a beneficial haemostatic effect of TA leading to decreased transfusion. ${ }^{9-13,15}$ These studies investigated all types of cardiac surgical patients with the majority of patients undergoing first time CABG. Repeat sternotomy results in increased blood loss as well as increased morbidity and mortality. ${ }^{18}$ The majority of blood transfusions occur in reoperative cardiac surgery and we therefore targeted this population to be evaluated. No study, to date, has assessed the effect of TA on reoperative valve replacement.

In the last decade, several drugs have been studied to reduce perioperative blood loss in cardiac surgery. ${ }^{19-22}$ Aprotinin is a serine protease inhibitor that has been the most thoroughly investigated for its effect on blood loss during cardiac surgery reviews. , $^{8,2,23,24}$ For many years, cardiopulmonary bypass surgery has been thought to be associated with increased fibrinolysis ${ }^{25-27}$ that is a major contributor to bleeding. ${ }^{28}$ The cause of increased bleeding after ECC has nor been elucidated but it is thought to be due to platelet dysfunction as well as to activation of the coagulation cascade leading to excessive fibrinolysis. ${ }^{29,30}$

The lysine analogues such as $\xi$-aminocaproic acid and TA bind to human plasmin to inhibit fibrinolysis. Tranexamic acid is seven to 10 times more potent than $\xi$-aminocaproic acid and has the same low toxicity. The antifibrinolytic effect of TA is the result of reversible complex formation with plasminogen and plasmin to inhibit fibrinolysis and prevent disruption of formed fibrin clots. Tranexamic acid has been shown to preserve platelet ADP during $\mathrm{ECC}^{31}$ and produces an antifibrinolytic effect by competitively inhibiting the activation of plasminogen to plasmin. Thus, TA inhibits plasmininduced degradation of fibrin and preserves the integrity of clots. A previous study demonstrated that patients who received a $10 \mathrm{~g}$ bolus of TA resulted in an effective reduction of blood transfusion ${ }^{10}$ and therefore this regime was employed in the present study. Other investigations into the dose-response relationship of TA indi- cate that a bolus followed by an infusion is also effective in decreasing bleeding after extracorporeal circulation. ${ }^{31}$ The timing of TA administration was prior to skin incision and after induction of anaesthesia as has been shown to be effective in previous studies. ${ }^{9,11,12,14,32}$ Some case reports suggest that, due to an association of hypercoagulable events with antifibrinolytics, ${ }^{33,34}$ the timing of administration of antifibrinolytics is most beneficial shortly after heparinization but before initiating cardiopulmonary bypass. ${ }^{\mathrm{a}}$

Patient selection included patients undergoing reoperative cardiac surgery because this population of patients have a considerable risk of perioperative bleeding and transfusion requirements. ${ }^{18}$ Specifically, valvular surgery patients were targeted because of the theoretical risk of coronary artery bypass graft thrombosis. We recognised the risk of thrombosis because of a previous study had indicated concern about the use of aprotinin during reoperative myocardial revascularization. ${ }^{35}$ Also, a recent study supported the possibility of vein-graft occlusion and increased risk of myocardial infarction in patients receiving aprotinin therapy, ${ }^{36}$ thus supporting our choice to exclude patients enrolled for aortocoronary bypass grafting.

The amount of blood loss in this study was higher than in previous published investigations due to the greater risk of bleeding in the reoperative population studied. In addition, this study attempted to assess all intraoperative blood loss by measuring sponge and drape blood content which may contribute to higher blood loss measurements. This is a potential short-coming of this study since the blood loss estimation may be less accurate. Despite this, the reduction of postoperative blood loss and transfusion was statistically significant. Our study results indicate a more beneficial role of TA likely because of the population studied. The postoperative blood loss and transfusion requirements were higher than in previous investigations and, therefore, differences between the two groups studied were more apparent. There was a higher mortality rate, $21 \%$, in the placebo group than in the TA group, $4.5 \%$, although this was not statistically significant. However, except in the case of pulmonary haemorrhage, the deaths were not thought to be due to haemorrhagic postoperative complications. In this centre, a recent study demonstrated comparable early mortality rates of between 10.6 and $17.4 \%$ in reoperative patients undergoing valve replacement. ${ }^{37}$

This study analyzed the effect of prophylactic administration of TA on bleeding and blood transfusion in patients undergoing reoperative cardiac valve replace-

\footnotetext{
a As discussed in Gravlee, G.P. Anesthetic management of cardiopulmonary bypass. 1996 ASA Annual refresher course lecture \#431.
} 
ment. The results suggest that TA may be used effectively in this way to reduce blood loss and the need for transfused blood products in patients undergoing complicated cardiac surgery involving repeat sternotomy and valvular surgery. Thus, in this specific population of cardiac surgical patients, prophylactic antifibrinolytic therapy appears to be appropriate and warranted.

\section{Acknowledgements}

Tranexamic acid used in this study was kindly supplied by KABI Pharmacia.

Funding to P.J.D. was provided in part from a UBC summer research award and an International Society for Cardiovascular Surgery fellowship.

The authors wish to thank Janet Lee Haines for her computer expertise during this project.

\section{References}

1 Harker LA, Malpass TW, Branson HE, Hessel EA Slichter SJ. Mechanism of abnormal bleeding in patients undergoing cardiopulmonary bypass: acquired transient platelet dysfunction associated with selective granule release. Blood 1980; 56: 824-34.

2 Royston D, Bidstrup BP, Taylor KM, Sapsford RN. Effect of aprotinin on need for blood transfusion after repeat open-heart surgery. Lancet 1987; II: 1289-91.

3 Lemmer JH Jr, Stanford W, Bonney SL, et al. Aprotinin for coronary bypass operations: efficacy, safety, and influence on early saphenous graft patency. A multicenter, randomized, double-blind, placebo-controlled study. J Thoracic Cardiovasc Surg 1994; 107: 543-53.

4 Biagini $A$, Comite $C, R$ usso $V$, et al. High dose aprotinin to reduce blood loss in patients undergoing redo open heart surgery. Acta Anaesthesial Belg 1992; 43; 181-6.

5 Cosgrove DM III, Heric B, Lytle BW, et al. Aprotinin therapy for reoperative myocardial revascularization: a placebo-controlled study. Ann Thorac Surg 1992; 54: 1031-8.

6 Minami K, Notohamiprodjo G, Buschler $H$, Probaska W, Reichelt W, Korfer $R$. Alpha-2 plasmin inhibitor-plasmin complex and postoperative blood loss: doubleblind study with aprotinin in reoperation for myocardial revascularization (Letter). J Thorac Cardiovasc Surg 1993; 106: 934-5.

7 Verstraete $M$. Clinical application of inhibitors of fibrinolysis. Drugs 1985; 29: 236-61.

8 Royston D. Blood-sparing drugs: aprotinin, tranexamic acid, and $\xi$-amoncaproic acid. Int Anesthesiol Clin 1995; 33: 155-79.

9 Horrow JC, Hlavacek J, Strong $M D$, et al. Prophylactic tranexamic acid decreases bleeding after cardiac operations. J Thorac Cardiovasc Surg 1990; 99: 70-4.
10 Karski JM, Teasdale SJ, Norman P, et al. Prevention of bleeding after cardiopulmonary bypass with high-dose tranexamic acid. Double-blind, randomized clinical trial. J Thorac Cardiovasc Surg 1995; 110: 835-42.

11 Horrow JC, Van Riper DF, Strong $M D$, Brodsky $I$, Parmet JL. Hemostatic effects of tranexamic acid and desmopressin during cardiac surgery. Circulation 1991; 84: 2063-70.

12 Tau TM, Carson S, Weisel RD, et al. The effect of warm heart surgery on postoperative bleeding. J Thorac Cardiovasc Surg 1992; 103: 1155-63.

13 Rousou JA, Engelman RM, Flack JE III, Deaton DW, Owen SG. Tranexamic acid significantly reduces blood loss associated with coronary revascularization. Ann Thorac Surg 1995; 59: 671-5.

14 Speekenbrink RGH, Vonk ABA, Wildevuur $C R H$, Eijsman $L$. Hemostatic efficacy of dipyridamole, tranexamic acid, and aprotinin in coronary bypass grafting. Ann Thorac Surg 1995; 59: 438-42.

15 Coffey A, Pittmam J, Halbrook H, Fehrenbacher J, Beckman D, Hormuth $D$. The use of tranexamic acid to reduce postoperative bleeding following cardiac surgery: a double-blind randomized trial. Am Surg 1995; 61: 566-8.

16 Fremes SE, Wong BI, Lee E, et al. Metaanalysis of prophylactic drug treatment in the prevention of postoperative bleeding. Ann Thorac Surg 1994; 58: 1580-8.

17 Øvrum $E$, Holen $E A$, Abdelnoor $M$, Øystese $R$, Ringdal $M L$. Tranexamic acid (Cyklokapron) is not necessary to reduce blood loss after coronary artery bypass operations. J Thorac Cardiovasc Surg 1993; 105: 78-83.

18 Bracey $A W$, Radovancevic $R$, Radovancevic $O$, McAllistair HA Jr, Vaughn WK, Cooley DA. Blood use in patients undergoing repeat coronary artery bypass graft procedures: multivariate anaylsis. Transfusion $1995 ; 35: 850-4$.

19 Bidstrup BP, Royston D, Sapsford RN, Taylor KM. Reduction in blood loss and blood use after cardiopul. monary bypass with high dose aprotinin (Trasylol). J Thorac Cardiovase Surg 1989; 97: 364-72.

20 DelRossi $A J$, Cernaianu $A C$, Botros $S$, Lemole $G M$, Moore R. Prophylactic treatment of postperfusion bleeding using EACA. Chest 1989; 96: 27-30.

21 Salzman EW, Weinstein MJ, Weintraub RM, et al. Treatment with desmopressin acetate to reduce blood loss after cardiac surgery. A double-blind randomized trial. N Engl J Med 1986; 314: 1402-6.

22 Havel M, Teufelsbauer $H, K n o ̈ b l ~ P$, et al. Effect of intraoperative aprotinin administration on postoperative bleeding in patients underoing cardiopulmonary bypass operation. J Thorac Cardiovase Surg 1991; 101: 968-72.

23 Hardy J-F, Bélisle S. Natural and synthetic antifibrinolytics in adult cardiac surgery: efficacy, effectiveness and efficiency. Can J Anaesth 1994; 41: 1104-12. 
24 Hardy J-F, Desroches J. Natural and synthetic antifibrinolytics in cardiac surgery. Can J Anaesth 1992; 39 : 353-65.

25 Bloom $A L$. Activation of coagulation and fibrinogen loss after using extracorporeal circulation. J Clin Pathol 1963: 16 ; 558-61.

26 Umlas J. Fibrinolysis and disseminated intravascular coagulation in open heart surgery. Transfusion 1976; 16: 460-3.

27 Ekert $H$, Montgomery $D$, Aberdeen $E$. Fibrinolysis during extracorporeal circulation. Comparison of the effects of disc and membrane oxygenators. Circ Res 1971; 28: 512-7.

28 Pbillips LL, Malm JR, Deterling RA. Coagulation defects following extracorporeal circulation. Ann Surg $1963 ; 157: 317-26$.

29 Kucuk O, Kwaan HC, Fredrickson J, Wade L, Green D. Increased fibrinolytic activity in patients undergoing cardiopulmonary bypass operation. Am J Hematol 1986; 23: 223-9.

30 Harker LA. Bleeding after cardiopulmonary bypass (Editorial). N Engl J Med 1986; 314: 1446-8.

31 Soslau G, Horrow J, Brodsky I. The effect of tranexamic acid on platelet ADP during extracorporeal circulation. Am J Hematol 1991; 38: 113-9.

32 Horrow JC, Van Riper DF, Strong MD, Grunewald KE, Parmet $J L$. The dose-response relationship of tranexamic acid. Anesthesiology 1995; 82: 383-92.

33 Bennett S. Electrocardiographic ST segment changes associated with aprotinin and reversed with heparin in two patients having coronary artery reoperations. J Cardiothorac Vasc Anesth 1994; 8: 202-5.

34 Umbrain V, Cristiaens F, Camu F. Intraoperative coronary thrombosis: can aprotinin and protamine be incriminated?. J Cardiothorac Vasc Anesth 1994; 8: 198-201.

35 Emdadi A, Jamieson WRE, O'Connor JP, et al. Experience with aprotinin in reoperative cardiac surgery. (Abstract) Can J Cardiol 1993; 9E: 118E.

36 van der Meer J, Hillege HL, Ascoop CAPL, et al. Aprotinin in aortocoronary bypass surgery: Increased risk of vein-graft occlusion and myocardial infarction? Supportive evidence from a retrospective study. Thromb Haemost 1996; 75: 1-3.

37 Tyers GFO, Jamieson WRE, Munro AI, et al. Reoperation in biological and mechanical valve populations: fate of the reoperative patient. Ann Thorac Surg 1995; 60: S464-9. 